\title{
The mystery of the fourth beat
}

\author{
F. van den Brink · I. Frenaij · R. van Tooren
}

Published online: 13 January 2016

(C) The Author(s) 2015. This article is published with open access at Springerlink.com

The ECG (see fig. 1 in the Question) shows a sinus rhythm of 97 beats per minute, a normal axis, a small QRS complex and only mild ST depression in all leads with slight elevation in aVR. Furthermore it shows a 4:1 ratio electrical alternans. During CPR, the patient suffered 3 left-sided and 5 right-sided rib fractures. As breathing caused negative intrathoracic pressure, the sternum collapsed shifting the heart to the left creating the 4:1 ratio electrical alternans. On intubation, a positive intrathoracic pressure was created causing the sternum to remain stable and the electrical alternans to disappear (Fig. 2). Although no definite cause for her out-ofhospital cardiac arrest has yet been found, a hereditary disease seems likely as her mother died suddenly of unknown cause at the same age. The patient made a full recovery.

Funding None.

Conflict of interest None declared.

Open Access This article is distributed under the terms of the Creative Commons Attribution License which permits any use, distribution, and reproduction in any medium, provided the original author(s) and the source are credited.

F. van den Brink $(\bowtie) \cdot$ I. Frenaij · R. van Tooren

St Antonius Hospital,

Nieuwegein, The Netherlands

e-mail: floris.s.van.den.brink@gmail.com

e-mail: f.van.den.brink@antoniusziekenhuis.nl 


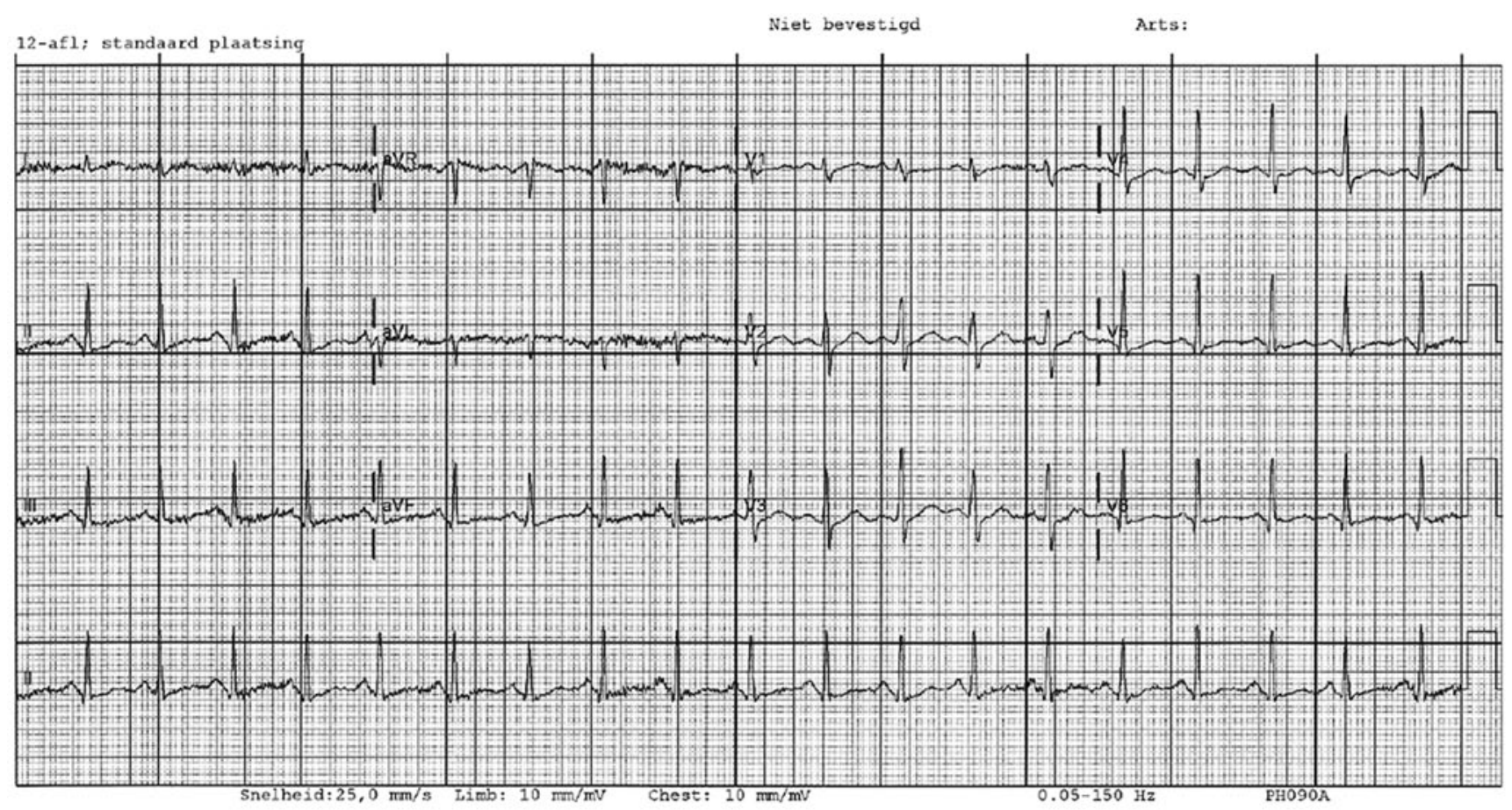

Fig. 2 ECG after intubation 